\section{Direitos e saúde reprodutiva de mulheres indígenas brasileiras: controle de natalidade e pluralismo}

Holanda, Marianna Assunção Figueiredo

Professora Adjunta - Programa de Pós-graduação em Bioética - Universidade de Brasília-DF. E-mail: marianna.holanda@gmail.com

PALAVRAS-CHAVE: Mulheres Indígenas, Pluralismo Bioético, Direitos Humanos, Direitos Reprodutivos, Bioética Feminista

Como a noção de direitos reprodutivos - desde uma perspectiva de direitos humanos ligados à superação das desigualdades de gênero, classe, raça e etnia - poderia dialogar com organizações sociopolíticas e de parentesco nas quais o corpo humano não é apenas individual mas compõe um povo/território. Algumas etnografias têm apontado para o desencontro entre a noção de "corpo" - individualizada pela biomedicina e pelo feminismo hegemônico/branco - que não permite compreender como as mulheres indígenas pensam a concepção e o controle de natalidade. Contudo, para além dos anseios e dilemas individuais, das negociações familiares e sociais que envolvem uma gestação, temos registrado uma intromissão cada vez mais institucionalizada do Estado no direito reprodutivo das mulheres brasileiras em geral, e das mulheres indígenas em particular. Esta especificidade envolve ainda a presença de organizações missionárias em aldeias e a imposição de moralidades externas às (bio)éticas indígenas. Identifica-se nestes desencontros conceituais e de projetos de mundo um contexto de carências: faltam acesso à informação, aos direitos e às políticas públicas de saúde específicas e diferenciadas por parte das mulheres indígenas e faltam pesquisas e políticas que abordem a apropriação e reflexão destas mulheres sobre seus direitos, aliadas às suas diferentes maneiras de pensar o corpo, a concepção, a gestação, o parto e o pós-parto - bem como suas práticas tradicionais de controle de natalidade e as questões do aborto pré e pós-natal para além de uma esfera que as criminaliza.

AGRADECIMENTOS. Às mulheres indígenas do Xingu, em especial às Kamayurá.

\section{REFERÊNCIAS}

[1] R. L. Segato. Antropologia e Direitos Humanos: Alteridade e Ética no movimento de expansão dos direitos universais. Mana vol.12 no.1 Rio de Janeiro Apr. (2006)

[2] D. L. Hodgson. "These are not our priorities": Maasai Women, Human Rigths, and the Problem of Culture. Philadelphia: U. Penn Press, (2011).
[3] M. Lugones. Colonialidad y Género. Tabula Rasa. Bogotá - Colombia, No.9: 73-101, julio-diciembre (2008).

[4] A. Sacchi, M. Gramkow. Gênero e Povos Indígenas. Rio de Janeiro, Brasília: Museu do Índio/ GIZ /FUNAI, (2012).

[5] C. Coimbra Jr., L. Garnelo. Questões de saúde reprodutiva das mulheres indígenas no Brasil. Centro de Estudos em Saúde do Índio de Rondônia (CESIR) Universidade Federal de Rondônia, (2002). 